NBER WORKING PAPER SERIES

\title{
POLICY UNCERTAINTY AND PRIVATE INVESTMENT IN DEVELOPING COUNTRIES
}

Dani Rodrik

Working Paper No. 2999

\author{
NATIONAL BUREAU OF ECONOMIC RESEARCH \\ 1050 Massachusetts Avenue \\ Cambridge, MA 02138 \\ June 1989
}

This paper was started at the World Bank, and has benefitted from the reactions and comments of numerous colleagues there. I owe special thanks to Ataman Aksoy, Patrick Conway, Riccardo Faini, Gerry Helleiner, Don Keesing, Ramon Lopez, Kazi Matin, Jaime de Melo, John Nash, Gary Purse11, and Vinod Thomas. The views expressed here are my own and should not be attributed to the World Bank or its affiliated organizations. This paper is part of NBER's program in International studies. Any opinions expressed are those of the author not those of the National Bureau of Economic Research. 
NBER Working Paper \#2999

June 1989

\title{
POLICY UNCERTAINTY AND PRIVATE INVESTMENT IN DEVELOPING COUNTRIES
}

\begin{abstract}
A resurgence in private investment is a necessary ingredient of a sustainable recovery in heavily-indebted developing countries. Policy reforms in these countries involve a serious dilemma, especially when they include structural and microeconomic features. On the one hand, entrepreneurs, workers, and farmers must respond to the signals generated by the reform for the new policies to be successful. On the other hand, rational behavior by the private sector calls for withholding investment until much of the residual uncertainty regarding the eventual success of the reform is eliminated. This paper shows that even moderate amounts of policy uncertainty can act as a hefty tax on investment, and that otherwise sensible reforms may prove damaging if they induce doubts as to their permanence. A simple model is developed to link policy uncertainty to the private investment response.
\end{abstract}

Dani Rodrik

John F. Kennedy School of Government Harvard University

Cambridge, MA 02138 


\section{INTRODUCTION}

Investment has been a clear casualty of the debt crisis in the heavilyindebted developing countries. In view of the investment collapse, how can these countries start to grow again? Public investment can hardly acquire a leading role anytime soon, given the fiscal crisis in most of the affected countries. And while improvements in productivity and capacity utilization can help, they are unlikely to be sufficient for self-sustaining growth. Clearly, then, a resurgence in private investment will be a necessary ingredient of any sustainable recovery.

Spurred by necessity more often than by desire, a large number of countries have undertaken comprehensive economic measures--both macroeconomic and structural--in recent years. ${ }^{1}$ while data are patchy, the private investment response to these reforms has so far been disappointing. As the continued predominance of capital flight demonstrates, few of these countries have managed to establish what a businessman might call an "acceptable investment climate". One important reason is the high degree of uncertainty regarding future policy. High-inflation countries like Argentina or Brazil have by now gone through a large number of falled stabilization programs. Even in countries like Turkey (since 1980) and Mexico (since 1983) which have maintained a basically consistent policy stance, there have been sharp, unpredicted changes in certain areas of policy-fiscal stance and trade policy in the former, trade and exchange-rate policies in the latter.

The prevalence of uncertainty of this sort creates an important dilemma.

1. For an overview of the reforms, as well as of the dismal investment consequences, see World Bank (1988). 
For policy reform to be successful, entrepreneurs, workers, and farmers have to respond to the signals generated by the reform. For example, outwardoriented exchange-rate and trade policies can serve their purpose only if the desired export response materializes. On the other hand, because physical investment is partly irreversible, rational behavior by the private sector calls for withholding investment until much of the residual uncertainty regarding the success of the reforms is eliminated. Without investment, reforms are less likely to prove sustainable; but investment will not be forthcoming in the presence of uncertainty as to future policies.

Hence the discomforting conclusion that the success of policies may depend in no small part on the psychology of private-sector expectations. A reform can end up being reversed for no other reason than a shared expectation that it will not last. Even if the initial expectation is not based on underlying fundamentals, it can prove self-fulfilling.

My purpose in this paper is not to discuss possible ways out of this dilemma, ${ }^{2}$ but to explore it with the help of a simple analytical model. By borrowing techniques from the new literature on hysteresis, I will show how uncertainty regarding the lasting power of reforms can act as a tax on investment, even when entrepreneurs are risk neutral. ${ }^{3}$ The model yields a simple formula that relates the size of the implicit tax to the subjective probability that the reforms will collapse and to the magnitude of the irreversibilities in the investment process. I stress here that the trade-off

2. This is done in Rodrik (1989a, b).

3. Two related papers deserve mention. Van Wijnbergen (1985) shows how less than perfectly credible reforms generate an option value for capital flight. Dornbusch (1988) stresses that a large premium will be required to convince the private sector to repatriate assets following a macroeconomic stabilization. 
between stability and reform, under reasonable conditions, may be quite steep, in the sense that even a small subjective probability of collapse may render harmful an otherwise sensible reform. ${ }^{4}$ To complete the model, I also discuss various ways in which the probability of reform collapse can be determined endogenously, in part as a function of the amount of investment that is coaxed out of the private sector. This leads to the possibility of multiple equilibria, wherein pessimistic expectations can be entirely self-fulfilling. Finally, I discuss some existing empirical work which is suggestive of the links between policy uncertainty and investment.

\section{THE INVESTMENT DECISION WITH POLICY UNCERTAINTY}

I will consider an economy where a policy reform has just been introduced. We conceptualize the situation prevailing before the reform as one where the entrepreneurs' yield from capital had been artificially depressed to $r-t_{0}$, where $r$ stands for the marginal product of capital and $t_{0}$ for the policy-induced distortion. We can think of $t_{0}$ as an explicit tax, or as the ultimate effect on profitability of an entire complex of distortions, such as import-substitution policies. The effect of the reform is to reduce $t_{0}$ to $t$, with $t<t_{0}$. (The possibility of a subsidy can be taken into account by allowing to be negative.) We denote the return to capital in its alternative employment by $r^{*}$. It is natural to suppose that the prereform policies have kept $r-t_{0}$ at a level no higher than $r^{*}$, that is $r-t_{0}$ $\leq r^{\star} \cdot 5$

4. This is related to Calvo (1986).

5. With no capital irreversibilities, equilibrium would of course require equality between the two sides. But, as we shall see, a gap between the respective returns in the two activities is possible once hysteresis is allowed for. 
$-4$.

The underlying model of the economy is left deliberately vague so that we can interpret the results broadly. In particular, we can think of the reform in question as being elther macroeconomic or microeconomic in nature. In the case of macroeconomic reform, $r$ - $t$ can be thought of as the domestic economywide return to capital (while the reform lasts) and $r^{*}$ as the yield on foreign assets. With microeconomic reform, $r$ - $t$ can be seen as the return in the activities promoted by reform (say, export-oriented sectors), with $r^{*}$ the return in other sectors of the economy. In both cases, the objective of the reform is to get capital to move in the desired direction: repatriation of flight capital in the first instance, and reallocation of capital from importsubstituting activities to export-oriented ones in the latter. The two interpretations will be developed simultaneously, as the analys is is relevant to both applications. Note further that our discussion will focus on the gap between $r$ and $r^{*}$, so we need not pin down each separately.

Policy uncertainty will be modeled in the form of a probability $\pi$ that the reform will be reversed. Treated as a constant by Individual entrepreneurs, $\pi$ measures the likelihood (per unit of time) of policy reversal. If and when the change occurs, we presume that $t$ will revert to $t_{0}$, its level prior to the reform. In this section, we will take $\pi$ as given. Section IV will discuss how it may be jointly determined with aggregate private investment.

Capital investment is partially irreversible in that there are sunk costs of entry and exit when physical capital is committed or moved from one sector to another. This aspect of the model, together with uncertainty, places it within the new literature on hysteresis. ${ }^{6}$ The general message of this 
literature is twofold: (i) with costly resource reallocation uncertainty can have large effects on behavior (even without risk aversion); and (ii) large enough changes in the environment can produce lasting effects on resource allocation even when the initial changes are eventually fully reversed.

Let us now consider the investment decision of an individual (riskneutral) entrepreneur at the time that the reform is put in place. For simplicity, suppose he owns a single unit of capital. His choice is between leaving his capital where it earns $r^{*}$ and moving it to where it would earn $r$ - $\tau$. The former option of capital flight (or of no re-allocation of capital) yields flow benefits of $r^{\star}$ per unit of time, with no uncertainty. Denoting the investor's discount factor by $\rho$, we can express the value of this first option as

(1) $v_{0}-r^{*} / \rho$,

where the subscript 0 refers to the case where the investor does not change behavior in response to the reform. Note that the investor who does not reallocate his capital when the reform is announced will certainly not do so if there is a reversal. Therefore, we do not have to be concerned separately with post-reversal returns in this case.

The value of having capital in the other activity can be determined as follows. ${ }^{7}$ Let $v_{1}$ denote the maximized value of holding a unit of capital in this latter sector at the moment that the reform is put in place. The magnitude of $v_{1}$ will depend on the possibility of reversal and the costs incurred if the reversal occurs. Similarly, let $v_{1}^{R}$ denote the maximized

(1988), and Pindyck (1988).

7. I am here following the discussion in Dixit (1987a), especially pp.19-21. 
value of having capital there once the reform is reversed. $\left[v_{1}-v_{1}^{R}\right]$ is the capital loss that accrues in case of reversal to those that have responded to the reform. Now $v_{1}$ has two components: one is the steady flow benefits of $r$ - $t$, and the other is the expected capital loss. Since the probability of reversal is $\pi$, the expected capital loss per unit of time is given by $\pi\left[V_{1} \cdot V_{1}^{R}\right]$. In present discounted value terms, then, the value of being in this sector is:

$$
v_{1}=\left((r-t)-\pi\left[v_{1}-v_{1}^{R}\right]\right) / \rho
$$

which yields:

(2) $\mathrm{v}_{1}=(\rho+\pi)^{-1}\left[(\mathrm{r}-\mathrm{t})+\pi \mathrm{v}_{1}^{\mathrm{R}}\right]$.

What remains is to determine $v_{l}^{R}$. Suppose for simplicity that once there is a reversal policies do not change, and that the flow return in this sector remains $\left(r-t_{0}\right)$ forever. Let exit costs (per unit of capital) be $\theta$. Then, it will pay to relocate capital after the reversal if the returns to staying put fall short of the returns to moving back, net of exit costs. That is, there will be a move back if:

$$
r-t_{0}<r^{*}-\rho \theta \text {, }
$$

where $\rho \theta$ is the flow equivalent of the exit costs. Capital will stay put if the inequality is reversed. The decision clearly depends on how large the reversal is, $i . e$. on the magnitude of $t_{0}$. $v_{1}^{R}$ in turn depends on the direction of this inequality:

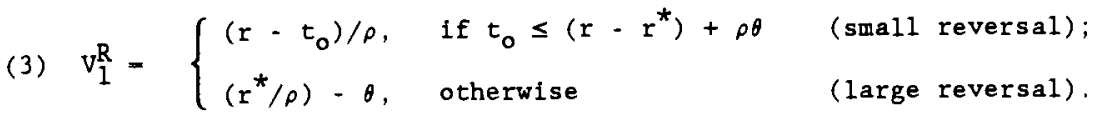


$v_{1}$ can then be written as follows:

(4) $v_{1}-(\rho+\pi)^{-1}\left[(r-t)+\pi \max \left[\left(r-t_{0}\right) / \rho,\left(r^{*} / \rho\right)-\theta\right\}\right]$

The question that we pose now is what it will take to get the entrepreneur to relocate his capital in response to the reform. Capital will move only if the net benefits of doing so are positive. Letting $\epsilon$ stand for entry costs (per unit of capital), the "trigger" level of parameter combinations which will make it worthwhile for capital to relocate is defined implicitly by:

(5) $v_{1} \geq v_{0}+\epsilon$.

Assuming that the potential reversal is "large", and substituting from (1) and (4), this requires

$$
(\mathbf{r}-t) \cdot \mathbf{r}^{\star} \geq \pi(\epsilon+\theta)+\epsilon \rho
$$

Or,

(6) $t \leq\left(\mathbf{r}-\mathbf{r}^{*}\right)-\epsilon \rho-\pi(\epsilon+\theta)$.

This is the central equation which links the entrepreneur's response to the magnitude of the reform, the ex-ante probability of sustainability, and the magnitude of capital irreversibilities (entry and exit costs). It shows how attractive domestic investment has to become before capital will react to the reform. The three terms on the right-hand side capture different requirements. First, $t$ must be low enough to make the after-tax return to domestic investment comparable to the yield on the alternative investment. In the absence of entry and exit costs, this would be the only requirement. Second, the reform must be sizable enough to compensate for the one-time cost of capital re-allocation (whose flow equivalent is $\epsilon \rho$ ). Third, and this is 
the key, the reform must also compensate for the likelihood of policy reversal (whose cost is given by $\pi[\epsilon+\theta]$ ).

Therefore, unless the reform is sufficiently large (i.e., t is sufficiently smal1), the desired investment response will not materialize. In fact, even a total elimination of the tax on investment (setting $t=0$ ) need not be sufficient when $\pi, \varepsilon$, and $\theta$ are large. Investors need to be compensated for entry costs and against the probability of reversal.

Equation (6) shows that potential unsustainability acts here just as a tax on investment. To see the magnitude of this tax, let us ask the question: what is the size of the investment subsidy we would have to institute just to neutralize the discouraging effects of unsustainability? The answer obviously depends on entry and exit costs. Suppose $\epsilon+\theta-0$. . which corresponds to the case in which the sunk costs of entry and exit add up to three-quarters of the cost of installed capital. This does not seem a wildly unrealistic number, given the highly industry-specific nature of machinery, the costs of installation, bankruptcy, hiring and firing labor, and so on. Then even a 10 percent probability of reversal requires an investment subsidy of 7.5 percentage points to offset its adverse effects on investment. This is a sizable number, as it is two-to-three times what reasonable (real) interest rates look like, and is probably of the same order of magnitude as the distortions imposed on returns to capital by pre-existing interventionist policies. A 20 percent probability of collapse would call for a subsidy of 15 percentage points. Moreover, the trade-off would look much worse were we to allow for risk-aversion.

We can conclude that even small amounts of uncertainty regarding the staying power of reforms can have substantial depressing effects on investment. Another way of saying the same thing is that domestic real interest rates must carry substantial premia over foreign rates in the 
presence of policy uncertainty.

The above discussion applies to the case where the reversal, were it to occur, would be large enough to make it profitable for investors to move their capital out. For small reversals, the analogue of expression (6) is:

$\left(6^{\prime}\right) t \leq\left(r-r^{*}\right)-\epsilon \rho-[\pi /(\rho+\pi)] t_{0}$.

Now the magnitude of the reversal $\left(t_{0}\right)$ appears explicitly as it determines post-reversal profitability directly. Notice that for discount rates that are small relative to the reversal probability, $\pi /(\rho+\pi)$ will be close to unity. Hence, this expression makes clear that investors will demand almost full compensation for the reversal, even though the probability of the reversal itself may be small. Suppose for example that $\pi-0.10$ and $\rho=0.025$. Then, investors will require a premium over $r^{*}$ which is 80 percent $(0.1 / 0.125)$ of the size of $t_{0}$, even though the probability of reversal is only 10 percent. The disproportionate response is due to the assumption that a collapsed reform will never revive--at least not in the same form or anytime soon. Once again, a large investment subsidy may be needed to offset the effect of uncertainty. This discussion highlights an important disadvantage of the gradualist approach to policy reform. The problem with gradualism is that when capital exhibits hysteresis small changes in policy will be insufficient to make any difference to resource allocation. But there is another side to the coin: Policy reversals need not take the economy back to square one, provided sufficient investment can be coaxed out of the private sector in the meantime: in the small reversal case above $\left(t_{0} \leq\left(r-r^{*}\right)+\rho \theta\right)$ capital that responds to the reform will remain in place even when the reform is aborted. In other words, reforms that are initially successful can create a momentum that outlives their eventual collapse.

This framework also sheds 1 ight on an important trade-off between reform 
$-10$.

and stability. When a policy reform is introduced, it is almost inevitable that the private sector will view it as less than one hundred percent sustainable. The reasons are many. At one level, there will be the expectation that the political economy configuration that supported the earlier policies may resurface. At another, since new policies take the economy into uncharted terrain, there will be the legitimate fear that unexpected consequences will lead to reversal. In view of the model presented here, the danger is that the uncertainty thereby created may well outweigh the beneficial effects of the reform.

To see this, suppose we start out with a distorted, but entirely sustainable policy configuration (with $\pi-0$ initfally). The government then introduces a reform, as before, which reduces the distortion from $t_{0}$ to $t$. But the new polfcy comes at the expense of a subjective probability, perhaps quite smal1, that the reform will not last: $\pi$ now turns positive. The question we pose is: how small must $\pi$ be for the policy reform to remain a good idea?

Take first the large reversal case. The direct benefit to the potential investor rises by $t_{0}-t$, thanks to the reform, while the opportunity cost of investment increases by $\pi(\epsilon+\theta)$, thanks to the induced uncertainty [see (6)]. Clearly, then, the reform will increase the net incentive to invest only if

$$
t_{0}-t>\pi(\epsilon+\theta) \text {. }
$$

Or if:

$$
\pi<\left(t_{0}-t\right) /(\epsilon+\theta) \text {. }
$$

This is in fact a stringent requirement. Suppose, for instance, that the reform increases the investor's direct return from capital by 10 percentage points $\left(t_{0}-t=0.1\right)$, which is quite large by any standard. Let $(\epsilon+\theta)$ 
equal 0.75 as before. Then, the subjective probability that the reform will collapse must be less than 13.3 percent for a net investment incentive to exist. And even when the subjective probability is lower than this threshold, the net investment incentive will be much smaller than the direct effect as long as the reform comes with a positive $\pi$.

Much the same holds for the small reversal case. Now, the opportunity cost rises by $[\pi /(\rho+\pi)] t_{0}$, so that the analogous condition can be written $t_{0}-t>[\pi /(\rho+\pi)] t_{0}$,

or, $\pi<\rho\left[\left(t_{0}-t\right) / t\right]$.

Notice that this condition will always hold for $t=0$, as the right-hand side of the inequality then goes to infinity. A complete elimination of the policy distortion therefore necessarily increases net investment incentives when the feared reversal is "smal1". But half-hearted reforms may backfire, as before. Suppose, for instance, that $\rho=0.10, t_{0}=0.10$, and $t=0.05$, so that the reform increases the direct return to capital by 5 percentage points. Then $\pi$ must be less than 10 percent for the induced policy uncertainty not to outweigh this direct effect.

The above examples are somewhat contrived in the sense that the role of policy uncertainty prior to reform has been ignored. This is particularly misleading when the reform in question involves macroeconomic stabilization. Near the end of the typical populist cycle (see Sachs, 1989, and Dornbusch and Edwards, 1989), the exchange rate becomes vastly overvalued, foreign reserves run out, and inflation starts to climb. The economic environment becomes ripe with uncertainty. We would then expect a well-designed macroeconomic reform program to reduce uncertainty (i.e., reduce $\pi$ ), not increase it. 
But, many microeconomic programs, and economic liberalization measures in particular, may replace what are in effect distorted but sustainable incentive regimes with less sustainable policies. ${ }^{8}$ Frequently such reforms are the price paid for assistance from the multilateral organizations, and are implemented with little regard to their consistency with the underlying political economy, 9 or, as also happens occasionally, with macroeconomic stability. 10 It is in such contexts that the framework analyzed here comes into its own. As the discussion above makes clear, even a small amount of uncertainty as to its survival may be too high a price to pay for an otherwise sensible reform.

\section{AGGREGATE INVESTMENT}

So far, we have looked at the investment decision of an individual entrepreneur. It is a short step now to determine the aggregate investment response as a function of $\pi, t$, and other parameters. Let us assume that there are $\mathrm{N}$ investors, each with a single unit of capital at their disposal.

8. There is nothing inherently unsustainable in a regime riddled with price distortions. A heavy dose of, say, trade protection can be sustained for a distortions. A heavy dime (cf. Indonesia, India), provided the overall macroeconomic framework is well managed (see Rodrik, 1988b). Small fiscal deficits and realistic exchange rates are key aspects of the requisite macro management.

9. Incentive systems are hard to change because they reflect the general equilibrium of various political and distributional forces at work. Since the underlying distribution of political power is unlikely to change very rapidly, any radical price reform must, as a rule, face the risk of failure. For an overview of the political obstacles, see Nelson (1984), Haggard and Kaufman (1988), and Lindenberg (1988).

10. Two important examples come to mind. Trade liberalization frequently leads to a reduction in government revenues, aggravating macroeconomic instability. Financial liberalization also typically leads to instability in the banking sector, and may increase the inflation rate by decreasing demand for base money. See Rodrik (1989a) for further discussion and examples. 
If all investors were alike, then total investment would be either 0 or $\mathrm{N}$, depending on which direction the inequality in (6) goes. More realistically. we can envisage investors aligned on a continuum indexed by some relevant parameter. For purposes of illustration, let investors differ by their entry costs, $\epsilon \in[0, \infty)$. Let $\epsilon$ be distributed according to the probability distribution function $f(\epsilon)$. Further, in general equilibrium the differential in the marginal products of capital will be a decreasing function of the amount of capital that is reallocated. So we can write,

$$
r-r^{*}=\Delta(I), \quad \Delta^{\prime}<0, \quad \Delta^{\prime \prime}<0,
$$

where I stands for the investment response to the reform.

Now define $\epsilon^{\star}$ as the cut-off point at which expression (6) holds as an equality: 11

(7) $\epsilon^{\star}-(\rho+\pi)^{-1}[\Delta(I)-t-\pi \theta]$.

Since all investors with entry costs below $\epsilon^{*}$ will choose to invest, the aggregate investment function can be written as follows:

(3.8) $I=N \int_{0}^{\epsilon^{*}} f(\epsilon) d \epsilon$.

It can be checked easily that aggregate investment is decreasing in $\pi$,

$$
\begin{aligned}
\mathrm{dI} / \mathrm{d} \pi & -\mathrm{Nf}\left(\epsilon^{*}\right) \mathrm{d} \epsilon^{*} / \mathrm{d} \pi \\
& =-\operatorname{Nf}\left(\epsilon^{*}\right)\left(\epsilon^{*}+\theta\right) /\left[(\rho+\pi)-\operatorname{Nf}\left(\epsilon^{*}\right) \Delta^{\prime}\right] \\
& <0 .
\end{aligned}
$$

11. I am here assuming the large-reversal case. The analysis of the other case is similar. 
This defines a downward sloping investment schedule (denoted by II in Figure 1). A reduction in $t$ will shift this curve to the right, i.e. more investment will be forthcoming for any given probability of pollcy reversal.

\section{ENDOGENIZING THE PROBABILITY OF REVERSAL}

The story above treated $\pi$, the subjective ex-ante probability of reversal, as a constant. As discussed earlier, in reality the magnitude of $\pi$ will depend in no small part on how successful the reform is in altering private-sector behavior. In the present framework, this is tantamount to incorporating a reverse linkage that goes from private investment to $\pi .12$ To illustrate the implications, we can extend the model to include this possibility.

There are several reasons why higher levels of investment (I) would lead to a lower probability of future reversal of reform $(\pi)$. We briefly discuss three particularly likely candidates.

(a) Political economy and creating entrenched interests. The greater the investment response, the more likely that entrenched interests will be created in favor of the continuation of the reform. Once entrepreneurs move into export sectors, they can be expected to constitute a lobby in favor of outward-oriented policies such as trade liberalization and realistic exchange rates. Labor unions whose membership is located predominantly in exportables

12. Of course, there are other reasons why investors may fear a reversal, and therefore alternative ways of endogenizing $\pi$. The possible time-inconsistency of policy is one such reason, on which see Barro and Gordon (1983), Staiger and Tabellini (1987), and Faini (1989), among others. Doubts about the true objectives of the government are another (Persson and van Wijnbergen, 1987, Rodrik, 1988a). 
are less likely to militate in favor of large real wage adjustments than those sheltered behind trade barriers. Similarly, flight capital that is repatriated and invested in domestic physical assets gives up the "exit" option, and must therefore rely on "volce" (Hirschman, 1970). For these reasons, we would expect a reform to receive greater political support when the desired reallocation of capital and other resources is accomplished. We can then express the probability of reversal as a decreasing function of the investment response: $\pi-\pi(I)$, with $\pi^{\prime}()<$.0 .

(b) Effects on external balance and reserves. A different line of argument has to do with the adverse consequences of reform on external balance and foreign reserves when the desired response does not materialize.

Typically, reforming countries have precarious balance-of-payments positions to begin with. Reforms which do not bring about the desired response may increase the pressures. A trade liberalization, for example, will tend to worsen the current account. A macro stabilization may do the same to the extent that it relies on targeting the exchange rate on inflation rather than the external balance. Countries may then have no choice but to abort the reform when reserves fall below a certain threshold (see Froot, 1988, and Dornbusch, 1988). In turn, a reduction in capital flight or a vigorous export expansion would make it less likely that the external balance would deteriorate to that extent. Once again, the probability of reversal will be a negative function of the level of the investment response, allowing us to write $\pi=\pi(I)$, with $\pi^{\prime}()<$.0 .

(c) Effects on fiscal balance. Higher investment would be associated with a growing economy, and pressures to reverse course may then become less strong. Aside from the obvious political reasons for that, there is also a fiscal reason. When economic activity is buoyant, the government can raise resources more easily, and the fiscal deficit becomes more tractable without 
recourse to emergency measures. Let us spend a moment on how this linkage could be formalized.

Let us associate the collapse of the reform with a fiscal deficit getting so large that the government is forced to resort to policies which conflict with the prevailing reforms. Then we can interpret $\pi$ as the probability that the deficit $(\delta)$ grows beyond a certain point $(\bar{\delta})$. Since the government's tax revenues are positively related to the level of economic activity, this provides us with the reverse linkage between $I$ and $\pi$. Letting $\tau$ stand for the average tax rate on national income, y stand for GDP, and $\mu$ stand for other (net) public expenditures with some random component to them, we can write the deficit as follows:

$$
\delta=\mu-\tau \mathrm{y},
$$

and

$$
\begin{aligned}
\pi & =\operatorname{prob}(\mu \geq \bar{\delta}+\tau \mathrm{y}) \\
& =\mathrm{G}(\bar{\delta}+\tau \mathrm{y}),
\end{aligned}
$$

where $G($.$) is the density function, and G^{\prime}<0$. To complete the framework, we link GDP with investment via the economy's incremental capital-output ratio, $k$ $=\Delta I / \Delta y$. Then $\pi$ becomes a decreasing function of $I$,

$$
d \pi / d I=G^{\prime} \tau / k<0,
$$

since increased investment increases the tax base by expanding capacity.

In real economies, all of these reasons are likely to be operating simultaneously, reinforcing the negatively-sloped dependence of $\pi$ on I. Let $\pi \pi$ denote the locus of points which captures this relationship. Note that $\pi$ and I are now both decreasing functions of each other. Figure 1 displays some 
of the consequences.

In what could be considered to be the "normal" case, with II sloped more steeply than $\pi \pi$, a larger reform (i.e., a lower $t$ ) would yield in equilibrium a higher level of aggregate investment and a lower probability of policy reversal (Fig. 1(a)). But notice also the perverse possibility that a larger reform would increase $\pi$ and reduce I (Fig, l(b)). The latter case is possible when investment is highly sensitive to $\pi$, and $\pi$ in turn is very sensitive to investment. Finally, note that the negative slope of the two curves leads to a fundamental indeterminacy in outcomes. Multiple equilibria are possible, with some combining high rates of investment with low collapse rates, and others exhibiting low investment and a high probability of collapse (Fig. l(c)). With uncoordinated decision-making amongst multitudes of entrepreneurs, pessimistic expectations about the survivability of reform can prove self-fulfilling, even though they may not have been well-grounded in the goverment's intentions.

\section{AN OVERVIEW OF THE EMPIRICAL EVIDENCE}

The idea that policy instability can be detrimental to private investment is easy to accept, and conforms well with the way busineesmen see their world. As one businessman puts it, "[y]ou can make money under any policy situation as long as it doesn't change every fifteen minutes." 13 However, it is hard to deploy serious econometrics in support of the proposition. For one thing, there are conceptual and measurement problems: what is the relevant variable whose uncertainty is at issue, and how does one measure instability? In principle, the answers are supposed to come from a full-fledged model of

13. Quoted in The Washington Post, October 30, 1988, Business Section. 
investment behavior, but even the simplest models of investment with irreversibilites are difficult to implement empirically. Moreover, there is the thorny issue of the possible endogeneity of instability, as the previous section discussed. Even if these problems were solved, cross-sectional analysis would be seriously hampered by the absence of data on private investment levels in many developing countries.

If one is willing to relax one's econometric standards somewhat, the universe of admissible evidence broadens considerably. There is a fairly large literature that measures the impact of variability in the economic environment on some selected indicators of performance. While it is difficult to avoid the conclusion that much specification search goes into this literature, the bottom line appears to be that uncertainty (or instability, which typically serves as it proxy) is indeed harmful.

Among the most relevant of these studies are the ones that document the implications for saving and investment. In the Latin American context, Leff and Sato (1987) draw attention to the negative relationship between saving performance and instability in import supply. Stewart and Venieris (1985) find a similar negative relationship between saving and measures of sociopolitical instability. In an analysis of forty-seven countries, Kormendi and Meguire (1985) discover that monetary instability has a strong retarding effect on growth, which works partly by reducing the investment effort and partly by lowering the return to capital.

Many other studies concentrate on economic growth directly. In a study of twenty-five African countries,. Wheeler (1984) finds average growth rates to be significantly and negatively affected by political instability. Also in Africa, Helleiner (1986) provides evidence of a negative relationship between import instability and economic growth. Devarajan and de Melo (1987) find that the currency stability provided by membership in the Franc zone in Africa 
has increased growth rates on average by 0.4 percentage points relative to other sub-Saharan countries. The adverse effect of export instability on growth has been the subject of numerous empirical papers (see in particular Glezakos, 1973, Voivodas, 1974, and Ozler and Harrigan, 1988). Related to these are numerous other studies which demonstrate the negative effect of exchange-rate instability on export supply in LDCs (e.g., Caballero and Corbo, 1988, and Celasun and Rodrik, 1989).

Particularly relevant to the present discussion is a paper by Lopez (1989) that investigates the effects on growth and investment of trade policies as well as of instability in the real exchange rate. The sample includes observations for 25 or 35 LDCs over the two sub-periods of 1975-80 and 1981-85. Using trade policy indicators developed by Halevi (1988), Lopez is able to assess the cross-sectional effects of import and export restrictions separately. His chief findings are: (i) instability in the real exchange rate (measured by its coefficient of variation) has a strong and statistically significant negative effect on both investment and real income growth; (ii) the trade policy dummies are statistically insignificant in the investment regression; and (iii) export restrictions have some explanatory power in the growth regression, but import restrictions remain statistically insignificant. The negative relationship between real exchange rate variability, on the one hand, and investment and growth, on the other, is further confirmed by regressions reported by Edwards (1989). These results are indicative of the quantitative importance of policy stability. Getting prices right, through trade liberalization, plays a largely secondary role in determining investment levels. At worst, it may prove harmful if it aggravates instability.

Finally, a paper by Conway (1988) is noteworthy in that it focuses on private investment, rather than aggregate investment as in the previous 
studies: Conway applies a standard investment function to annual Turkish data for 1962-86. His regressions are augmented by adding a proxy for instability: the standard deviation of the real interest rate (but other variables would do as well since instability is highly correlated across key relative prices). This proxy comes out with a negative and highly significant coefficient, and, when it is included, the level of the real interest rate turns statistically insignificant. Disaggregating private investment, Conway finds that uncertainty has a uniformly depressing effect on manufacturing, transport, and housing sectors (with the effect on agriculture falling short of statistical significance at the 95 percent level). The strongest effect by far is observed in manufacturing investment. This is consistent with prior expectations, as the potential of policy reversals to do harm and the magnitude of irreversibilities are both presumably larger in manufacturing than elsewhere.

\section{CONCLUDING REMARKS}

The main message of this paper is that policy reforms that appear desirable on standard economic grounds will backfire when they induce doubts as to their likely survival. The danger is relatively small with welldesigned macroeconomic stabilization measures, as these aim to reverse unsustainable trends in inflation and deficits to begin with. It is much greater with structural reforms and liberalization measures. Hence the more positive message is that reform packages which emphasize policy stability and sustainability are likely to bring greater payoffs in terms of investment and growth than those which focus on economic liberalization and getting prices right. 


\section{REFERENCES}

Barro Robert, and David Gordon, 1983, "A Positive Theory of Monetary Policy in a Natural Rate Model," Journal of Political Economy 91(4), August, 589-610.

Caballero, Ricardo J., and Vittorio Corbo, 1988, "Real Exchange Rate Uncertainty and Exports: Multi-Country Empirical Evidence," World Bank, November.

Calvo, Guillermo, 1986, "Incredible Reforms," University of Pennsylvania, September.

Celasun, Merih, and Dani Rodrik, 1989, "Debt, Adjustment, and Growth: Turkey," in Jeffrey Sachs (ed.), Developing Country Debt and Economic Performance: Country Studies, Chicago and London: The University of Chicago Press, forthcoming.

Conway, Patrick, 1988, "The Impact of Uncertainty on Private Investment in Turkey," Department of Economics, University of North Carolina, December.

Dixit, Avinash, 1987a, "Entry and Exit Decisions of Firms with Fluctuating Real Exchange Rates," Princeton University, October.

, 1987b, "Hysteresis, Import Penetration, and Exchange Rate Pass-Through," Princeton University, November.

, 1987c, "Intersectoral Capital Reallocation Under Price Uncertainty," Princeton University, November.

Dornbusch, Rudiger, 1988, "Notes on Credibility and Stabilization," unpublished paper, MIT, November.

Dornbusch, Rudiger, and Sebastian Edwards, 1989, "Economic Crises and the Macroeconomics of Populism in Latin America: Lessons from Chile and Peru," unpublished paper, May.

Edwards, Sebastian, 1989, "Real Exchange Rates in the Developing Countries: Concepts and Measurement," NBER Working Paper No. 2950, April.

Faini, Riccardo, 1989, "Credibility, Investment, and the Real Exchange Rate," unpublished paper, Johns Hopkins University, Bologna, February.

Froot, Kenneth, 1988, "Credibility, Real Interest Rates, and the Optimal Speed of Trade Liberalization," Journal of International Economics.

Glezakos, C., 1973, "Export Instability and Economic Growth: A Statistical Verification," Economic Development and Cultural Change 21, 670-78.

Haggard, Stephan, and Robert Kaufman, 1988, "The Politics of Stabilization and Structural Adjustment," typescript.

Halevi, Nadav, 1988, "Trade Liberalization in Adjustment Lending," Trade Policy Division, The World Bank. 
Helleiner, Gerry K., 1986, "Outward Orientation, Import Instability, and African Economic Growth: An Empirical Investigation," in S. Lal1 and F. Stewart (eds.); Theory and Reality in Development: Essays in Honour of Paul Streeten, New York, St: Martin's Press.

Hirschman, A.O., 1970, Exit, Volce, and Loyalty, Cambridge, Harvard University Press.

Kormendi, Roger C., and Philip C. Meguire, 1985, "Macroeconomic Determinants of Growth: Cross-Country Evidence, Journal of Monetary Economics, 1985.

Krugman, Paul, 1988, "Deindustrialization, Reindustrialization, and the Real Exchange Rate," NBER Working Paper No. 2586.

Leff, Nathaniel H., and Kazuo Sato, 1987, "The Prospects for Higher Domestic Savings Rates in Latin America," Journal of Policy Modeling 9(4).

Lindenberg, Marc, 1988, "Making Economic Adjustment Work: The Politics of Policy Implementation," John F. Kennedy School of Government, Harvard University.

McDonald, Robert, and Daniel R. Siege1, 1986, "The Value of Waiting to Invest," Quarterly Journal of Economics 101, November.

Nelson, Joan, 1984, "The Political Economy of Stabilization," World Development 12 .

Ozler, Sule, and James Harrigan, 1988, "Export Instability and Growth," Working Paper No. 486, Department of Economics, UCLA, June.

Persson, Torsten, and Sweder van Wifnbergen, 1987, "Signaling, Wage Controls, and Monetary Disinflation Policy," The World Bank.

Pindyck, Robert S., 1988, "Irreversible Investment, Capacity Choice, and the Value of the Firm," American Economic Review 78(5), December.

Rodrik, Dani, 1989a, "How Should Structural Adjustment Programs Be Designed?," unpublished paper, John F. Kennedy School of Government, Harvard University.

, 1989b, "Credibility in Trade Reform: A Policymaker's Guide," The World Economy, March (forthcoming).

, 1988a "Promises, Promises: Credible Policy Reform via Signaling," NBER Working Paper No, 2600. (Forthcoming, Economic Journal, September 1989.)

1988b, "Closing the Technology Gap: Does Trade Liberalization Really Help?" NBER Working Paper No, 2654. (Forthcoming in Gerry Helleiner, ed., New Trade Theory and Industrialization in Developing Countries, oxford University Press.)

Sachs, Jeffrey, 1989, "Social Conflict and Populist Policies in Latin America," NBER Working Paper No. 2897, March.

Staiger, Robert W., and Guido Tabellini, "Discretionary Trade Policy and 
Excessive Protection," American Economic Review 77(5), December, 823-837.

Stewart, Douglas B., and Yiannis P. Venier1s, 1985, "Sociopolitical Instability and the Behavior of Savings in Less Developed Countries, " Review of Economics and Statistics, November.

van Wijnbergen, Sweder, 1985, "Trade Reform, Aggregate Investment and Capital Flight: On Credibility and the Value of Information, "Economics Letters 19, 369-72.

Voivodas, C.J., 1974, "The Effect of Foreign Exchange Instability on Growth," Review of Economics and Statistics 56, 410-12.

Wheeler, David, 1984, "Sources of Stagnation on sub-Saharan Africa," World Development, vol. 12, no. 1 .

World Bank, 1988, Adjustment Lending, PPR Policy \& Research Series, No. 1, Washington, DC. 


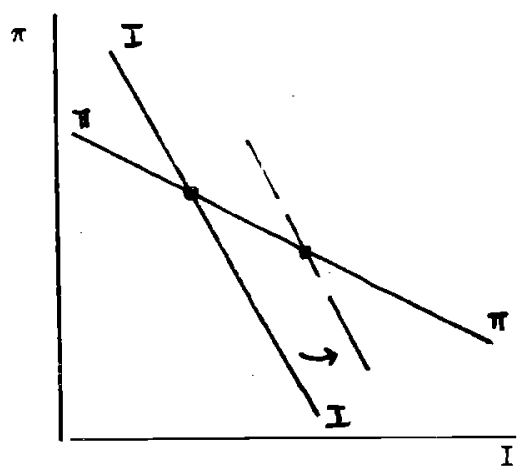

(a) reduction in $t$ increases $I$, reduces $\pi$

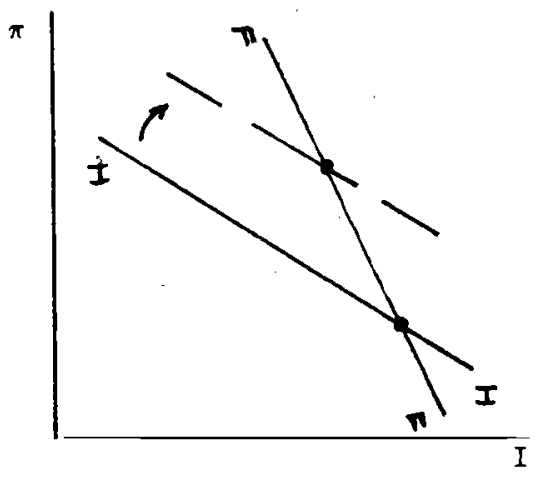

(b) reduction in $t$ reduces $I$, increases $\pi$

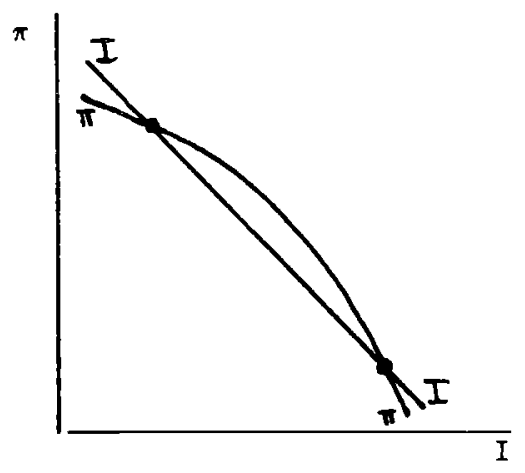

(c) multiple equilibria

Figure 1 